\title{
Lithosphere-atmosphere-ionosphere coupling as governing mechanism for preseismic short-term events in atmosphere and ionosphere
}

\author{
O. Molchanov ${ }^{1}$, E. Fedorov ${ }^{1}$, A. Schekotov ${ }^{1}$, E. Gordeev ${ }^{2}$, V. Chebrov ${ }^{3}$, V. Surkov ${ }^{1}$, A. Rozhnoi ${ }^{1}$, S. Andreevsky ${ }^{1}$, \\ D. Iudin ${ }^{4}$, S. Yunga ${ }^{3}$, A. Lutikov ${ }^{3}$, M. Hayakawa ${ }^{5}$, and P. F. Biagi ${ }^{6}$ \\ ${ }^{1}$ Inst. of the Physics of the Earth, Russian Academy of Sciences, Bolshaya Gruzinskaya 10, 123995, Moscow D-242, Russia \\ ${ }^{2}$ Inst. of Volcanology and Seismology, Far East Branch, Russian Academy of Sciences, Petropavlovsk-Kamchatsky, Russia \\ ${ }^{3}$ Geophysical Survey, Russian Academy of Sciences, Russia \\ ${ }^{4}$ Radiophysical Research Institute, Nizhni Novgorod, Russia \\ ${ }^{5}$ University of Electro-Communications, Chofu 1-5-1, Tokyo 182, Japan \\ ${ }^{6}$ University of Bari, Italy
}

Received: 26 July 2004 - Revised: 9 November 2004 - Accepted: 12 November 2004 - Published: 22 November 2004

Part of Special Issue "Precursory phenomena, seismic hazard evaluation and seismo-tectonic electromagnetic effects"

\begin{abstract}
We present a general concept of mechanisms of preseismic phenomena in the atmosphere and ionosphere. After short review of observational results we conclude: 1 . Upward migration of fluid substrate matter (bubble) can lead to ousting of the hot water/gas near the ground surface and cause an earthquake (EQ) itself in the strength-weakened area; 2 . Thus, time and place of the bubble appearance could be random values, but $\mathrm{EQ}$, geochemistry anomaly and foreshocks (seismic, SA and ULF electromagnetic ones) are casually connected; 3 . Atmospheric perturbation of temperature and density could follow preseismic hot water/gas release resulting in generation of atmospheric gravity waves (AGW) with periods in a range of 6-60 min; 4. Seismoinduced AGW could lead to modification of the ionospheric turbulence and to the change of over-horizon radio-wave propagation in the atmosphere, perturbation of LF waves in the lower ionosphere and ULF emission depression at the ground.
\end{abstract}

\section{Introduction}

Let us start from citation of the merited seismologist: "Seismology has reached a stage where its lofty goals cannot be pursued by seismologists alone.... A major interdisciplinary effort is needed to develop a prediction scheme based on multi-premonitory phenomena: it means that nearfield of future focal zone must be first identified, and then

Correspondence to: O. Molchanov

(oleg@molchanov.org) monitored for electrical, magnetic, acoustic, seismic, and thermal precursors simultaneously and continually... Unless we launch a concentrated interdisciplinary effort, we shall always be surprised by next major earthquake" (BenBenahem, 1995). Basing on observation results from special station Karimshino (Kamchatka, Russia) and some related data we believe that non-seismic events are helpful to work out the strategy (scientific basis) for earthquake (EQ) forecast but also these events are indicative for understanding of mechanisms of preseismic processes (stage of EQ preparation) and origin of EQ itself. In addition a problem of lithosphere-atmosphere-ionosphere coupling due to seismicity (LAICS) is well-discussed at present as a result of application of radiophysics and satellite recording methods. There are a lot of published evidences of non-seismic phenomena around date and in the epicenter's vicinity of large EQs from on the ground observations (see e.g. books by Rikitake, 1976; Scholz ,1990; Gokhberg et al., 1995; Hayakawa and Molchanov, 2002; and reviews e.g. by Parrot et al., 1993; Park, 1996; Liperovsky et al., 2000). We are going to review shortly only phenomena connected with appearance of the atmospheric and ionospheric perturbations and justified by statistics. For example, an appearance of electromagnetic Ultra-Low Frequency (hereafter ULF, frequency range $0.003-3 \mathrm{~Hz}$ ) emission is well-documented (Fraser-Smith et al., 1990; Molchanov et al.,1992; Kopytenko et al., 1993; Uyeda et al., 2002) and results on Seismo-Acoustic emission (Diakonov et al., 1990; Gorbatikov et al., 2002) look also as rather promising, but both ULF emission and highfrequency seismic emission from the underground can not 

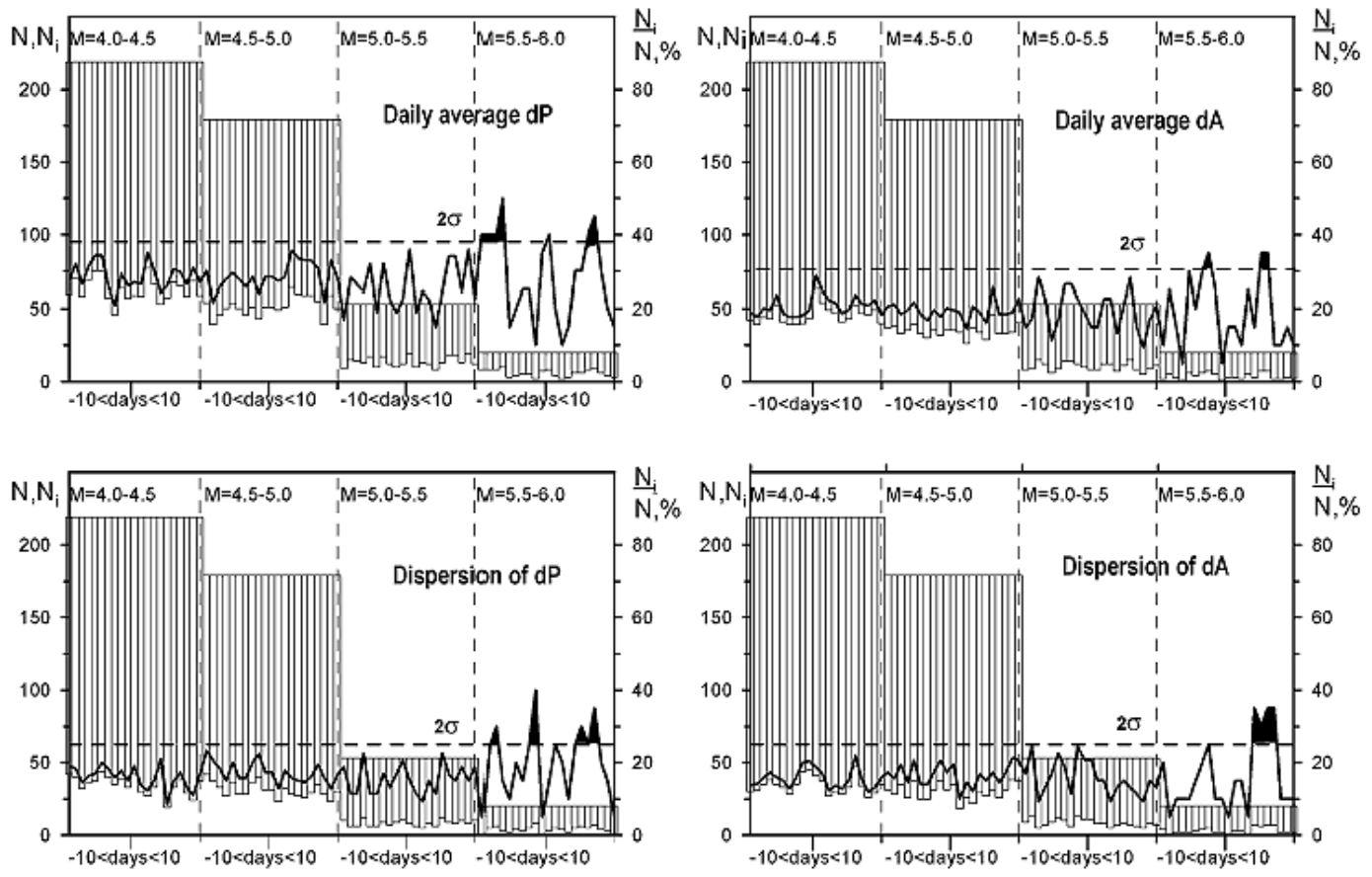

Fig. 1. Dependence of amplitude and phase anomaly on earthquake magnitude during 2001-2002 for the period from 10 days before to 10 days after the earthquake time. Top of the float bar is the number of days in the interval of $\mathrm{M}(\mathrm{N})$. Bottom of the float bar is the number of days in the same interval with data exceeding $\sigma(\mathrm{Ni})$. Solid line is Ni/N, and dotted line is the average of Ni/N+2 $\sigma$ (adopted from Rozhnoi et al., 2004).

produce essential impact in the upper atmosphere and ionosphere. From the other hand, results of vertical ionospheric sounding from the ground (Liperovsky et al., 2000) and of HF signal scattering in the atmosphere (e.g. Kushida et al., 1998, Fukumoto et al., 2002) are obviously related to our problem but they are not proofed by reliable statistics yet. In other words, we intend to present more or less convincing results to reveal mechanism of LAICS and discuss these mechanisms.

\section{Review of observational results to be explained}

We review five effects:

2.1 Seismo-induced modification of the VLF and LF subionospheric signals

VLF signal method is a well-known radio-physical method monitoring phase and amplitude of radio signals from navigational transmitters propagating inside the earth-ionosphere waveguide. If a transmitter frequency and receiver distance are fixed, then the observed VLF signal parameters depend mainly upon the reflection height determined by magnitude and gradients of electron density near the atmosphereionosphere boundary. Therefore, the VLF signal method has become the standard for recording short-time electron density variations in the lower ionosphere and upper atmosphere connected with the solar radiation (e.g. Roentgen flares), cosmic rays (Forbush effect), precipitation of energetic parti- cles, lightning-induced ionization, ionosphere modification by HF transmitters and, of course, atmospheric nuclear tests. The first suggestion to use this method in association with seismic activity was made by Russian scientists about 10 years ago (Gokhberg et al., 1989, Gufeld et al., 1992). Then, Japanese and Russian colleagues accumulated more data on anomalies in subionospheric propagation probably associated with earthquakes. They analyzed deviations from nighttime monthly averages of signal phase and claimed that the phase differences increased over a period from about onemonth to a few days before earthquakes. However, these results were not very convincing and justified by statistics.

Reliable VLF subionospheric signal effect related to the seismic activity was first reported by Hayakawa et al. (1996) in association with the great Kobe earthquake. They used so-called terminator time (TT) method of the data processing. Molchanov and Hayakawa (1998) have analyzed the data around 10 other strong earthquakes (magnitude $M>6$ ), in order to understand the main features of such an effect, and the following characteristics are emerged from their analysis: a) This effect is initiated a few days before a large earthquake and relaxed for a few days or weeks after it; b) It is mainly related to crustal earthquakes; c) It cannot be observed outside the sensitivity zone of VLF transmitter (first Fresnel zone) even for very large earthquakes (M>7); d) It appears when the resonant atmospheric oscillations with a period in range 5-11 days exist before an earthquake. They have stated that seismic influence on the VLF signal is explained by the generation of long-term gravity waves during an earthquake 


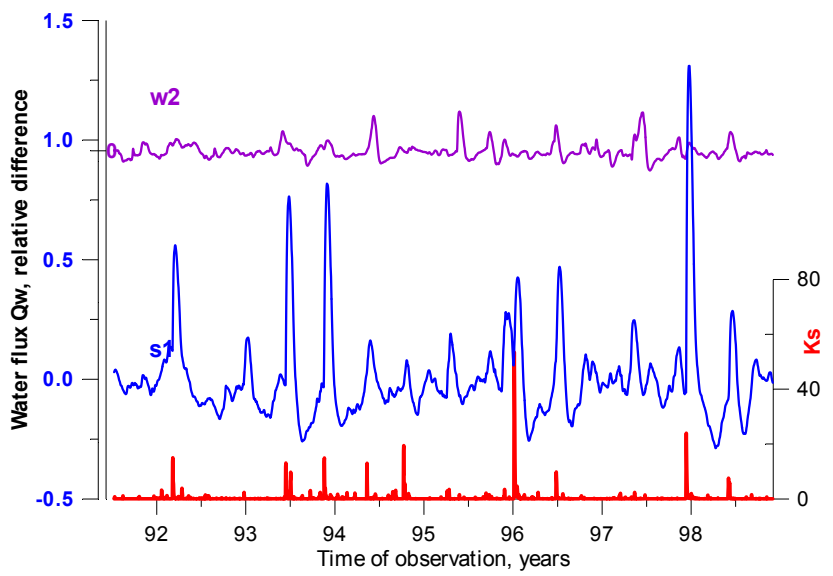

Fig. 2. Index of seismic activity $K s$ (below) and water flow rate variation in spring (s1) and well (w2) in Kamchatka area (adopted from Biagi et al., 2003).

process and their intensification at the heights of 70-90 km. In the latest papers it have been found a correlation of VLF phase/amplitude night-time oscillations in a range of periods from 20 min to several hours with seismic activity (Miaki et al., 2002; Shvets et al., 2002).

Simple theoretical estimations of the electron density perturbations connected with this effect have been produced (Hayakawa et al., 1996, Rodger and Cliverd, 1999) and more thorough consideration of the problem including the TT method has been presented by Soloviev et al. (2004).

Recent results in Kamchatka on this subject are rather similar to those obtained in Japan (Rozhnoi et al., 2004). LF transmitter located in Japan $(\mathrm{F}=40 \mathrm{kHz})$ was used; its wave path length is about $2300 \mathrm{~km}$. During the two year monitoring in the area of wave path sensitivity, 565 earthquakes with $M>4$ and 32 strong shocks with $M>5: 5$ have been registered. Some statistics is shown in Fig. 1. It is evident that VLF variations exceed twice dispersion $(2 \sigma)$ reliability level only for strong earthquakes $(M>5.5)$.

Let us discuss now the results on seismo-induced perturbations of LF signals. Biagi et al. (2001) and Biagi et al. (2004) discovered attenuation of the LF signals at the distances $300-500 \mathrm{~km}$ several days before EQs together with similar wave depression related to volcano eruption and seabottom gas release in Italy. The electric field of three LF broadcasting stations CLT ( $\mathrm{F}=189 \mathrm{kHz}$, Sicily, Italy), MCO ( $\mathrm{F}=216 \mathrm{kHz}$, France) and CZE (F=270 kHz, Czech Republic) has been monitored since 1997 at a receiving station in central Italy. During September-November 2002, they observed significant decreases in the signal of the CLT broadcasting station. No effect appeared on the MCO and CZE radio signals, which wave paths did not cross the Sicily region. On 6 September an earthquake with $\mathrm{M}=5: 6$ occurred offshore, about $40 \mathrm{~km}$ far from Palermo city (Sicily), starting an intense seismic crisis for more than one month. On 27 October the Etna volcano (Sicily) started an eruption that in January 2003 was still active. On 31 October an earth-

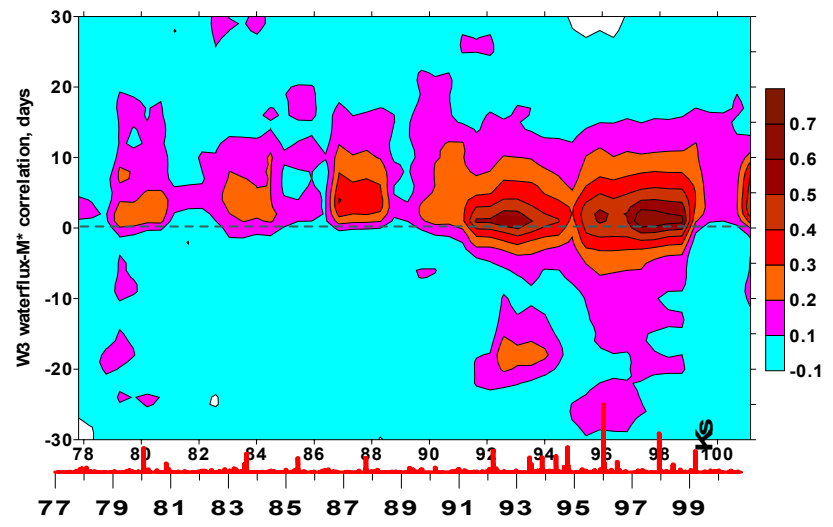

Fig. 3. Running correlation between seismic shock sequence and water flow rate variation in spring (s1) and in the interval \pm 30 days during 22 years in Kamchatka region (from Biagi et al., 2003).

quake with $\mathrm{M}=5: 4$ occurred at the border between Molise and Puglia regions (southern Italy) and, finally, in the period 3-6 November intense gas exhalations happened near the Eolie islands (southern Tyrrhenian sea). The decreases of CLT radio-signal demonstrate a clear relation to the previous activities with some premonitory behavior. Biagi et al. (2004) have supposed that changes in the troposphereground boundary zone and in the lower non-ionized atmosphere were the main candidates to justify the phenomenology they observed. These results can be also explained in terms of induced atmospheric gravity waves (AGW). The same conclusion have been drawn from recent observation of high-frequency scattering in the atmosphere associated with earthquakes. Kushida (1998), Fukumoto et al. (2002) using FM over-horizon signal reception $(76-78 \mathrm{MHz})$ have found intensification of the signals and fluctuations of the background 1-7 days before EQs in Japan. Fukumoto et al. (2002) have demonstrated that this scattering occurs in the troposphere.

\subsection{Geo-chemistry and water table variations}

Numerous reports on hydrology and gas release in association with large earthquakes have been made during last 10 20 years (King, 1986; Roeloffs, 1988; Voitov and Yunusov, 1996; Ghose et al., 1996; Wakita, 1996). One of the longest series of such observation was performed at Kamchatka area. As a result, it was possible to produce helpful statistics (Biagi et al., 2000, 2003). Here we show some results from paper by Biagi et al. (2003). Variation of the water flow rate is demonstrated in Fig. 2.

It is evident from Fig. 2 that data from the spring are more sensitive to seismicity than data in the well. This is probably connected with difference between a "pin-point" measurement in a well and the integrated large area registration in the spring, which has multi-root supply.

A correlation between the water flow rate and $K s$ is shown in Fig. 3 (see for details Biagi et al., 2003). Here the 


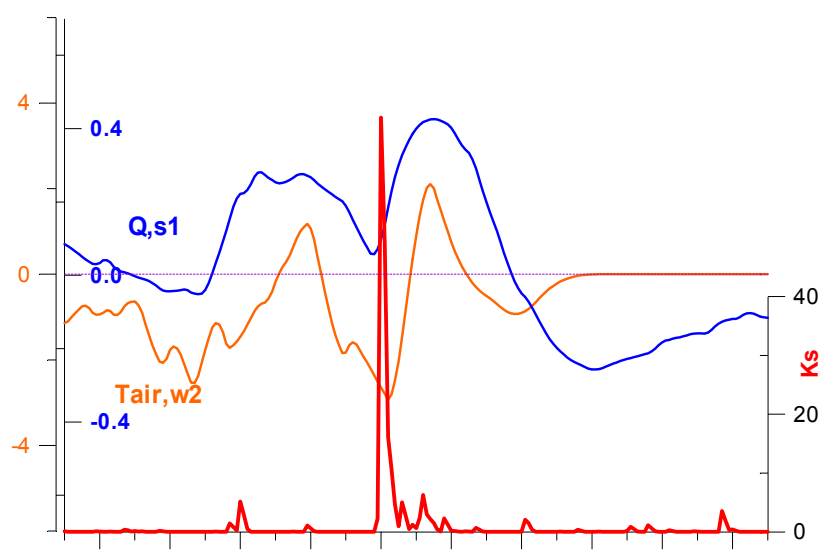

Fig. 4. Air temperature $T_{\text {air }}$ and water flow rate in spring $Q, \mathrm{~s} 1$ variation around date of large earthquake EQ 96 (1 January 1996; $\mathrm{M}=6.9, h=10 \mathrm{~km})$. Major time ticks here are 20 days and minor ticks are 10 days, time of EQ is shown by $K s$ spike (from Tronin et al., 2004).

correlation interval \pm 30 days is used. It can be noted that a reliable correlation with seismicity appears not only for the intervals after EQs but at least in several periods (1980-1981, 1991-1993, 1995-1998 years) some correlation exists for the intervals before EQs (usually several days before, but sometimes up to 30 days).

As for the problem of connection between seismo-induced gas-water phenomena and atmosphere-ionosphere environment, we demonstrate in Fig. 4 the comparison of the airtemperature and water flow rate for the recent strongest EQ shock in Kamchatka (see for details and other cases, Tronin et al., 2004). It shows an increase of the air temperature in the registration area, which is evidently connected with hot water release from the spring. We can conclude the following:

1. Seismo-induced water-gas release does exist and it is especially evident after integrated recordings in the springs, and from time to time in the wells.

2. A connection between seismo-associated water table and geochemistry events and the air temperature (probably also pressure) near the Earth surface can be seen.

3. Thus, a model of sporadic in space and twinkling in time source of atmosphere perturbations can be supposed in the interval $\pm 20-30$ days around time of large EQs.

2.3 Ground surface thermal variation observed from satellites

The modern operational space-borne sensors in the infra-red (IR) spectrum makes possible monitoring of the Earth's thermal field with a spatial resolution of $0.5-5 \mathrm{~km}$ and with a temperature resolution of $0.12-0.5^{\circ} \mathrm{C}$. Surveys are repeated every $12 \mathrm{~h}$ for the polar orbit satellites, and $30 \mathrm{~min}$ for geostationary satellites. The operational system of polar orbit satellites (2-4 satellites on orbit) provides whole globe survey at least every $6 \mathrm{~h}$ or more frequently. Such sensors may closely monitor seismic prone regions and provide information about the changes in surface temperature associated with an impending earthquake.

Natural phenomena and data availability stimulated the analysis of the long time series of thermal images in relation to earthquake hazard. Thermal observations from satellites indicate the significant change of the Earth's surface temperature and near-surface atmosphere layers. A lot of thermal anomalies prior to earthquakes related to high seismic areas have been reported in Middle Asia, Iran, China, Turkey, Japan, Kamchatka, India, Turkey, Italy, Greece and Spain. Case studies of thermal satellite data application were statistically proofed on long series of observations at Middle Asia by Tronin (1999) and Mediterranean area by Tramutoli et al. (2001). Tronin et al. (2004) has shown the presence of seismic thermal anomalies in Kamchatka peninsula also.

Results of thermal satellite data application for different areas lead to conclusions: 1) thermal anomalies appear about 6-24 days before and continue about a week after earthquake; 2) the anomalies are sensitive to crust earthquakes with a magnitude more than $4.5 ; 3$ ) the size of anomaly is $\sim 300 \mathrm{~km}$ in length and $\sim 90 \mathrm{~km}$ in width; 4) thermal anomaly has a mosaic internal structure with average element size about $40 \times 130 \mathrm{~km} ; 5)$ the amplitude of an anomaly is about 3- $6^{\circ} \mathrm{C}$; 6) thermal anomalies are attracted to large faults; 7) the nature of thermal anomalies is not clear now; 8) the response of water in wells and surface temperature in thermal anomaly on earthquake look similar; 9) increase of air and surface temperature as a consequence of the hot water eruption in a few days before strong earthquakes could induce atmospheric perturbations (Tronin et al., 2004).

Case studies of various remote sensing methods applications for earthquake have been reported recently. Pinty et al. (2003) have found significant surface moisture growth after the Gudjarat earthquake, 26 January 2001, using of MISR radiometer onboard of Terra satellite. Dey and Singh (2003) inform about evaporation change related to the same earthquake. Also we can mention numerous attempts to use cloud detection for earthquake research (Morozova, 1996).

\subsection{Modification of ionospheric turbulence}

Several reviews have been already published on satellite observations of electromagnetic and ionospheric perturbations apparently associated with seismic activity (Parrot et al., 1993; Gokhberg et al., 1995; Hayakawa, 1997; Liperovsky et al., 2000). It is not easy to interpret satellite observations. If the association is real, the seismic events under consideration are associated with long time duration physical phenomena. Publications of case studies were useful for triggering the attention to the phenomenon, but they are controversial as there is generally no way to reject the hypotheses of pure coincidences. This was the case of perturbations observed in ULF/ELF/VLF electromagnetic fields, plasma density and ion composition, fluxes of energetic particles (see review in 
Molchanov et al., 2002). Now, a basic problem with the derivation of statistical quantities from a moving satellite is the difficulty to respect hypotheses on stationarity and ergodicity and to separate time and space variations.

The only way to test the hypothesis of a correlation between satellite measurement and seismic activity is probably to multiply the low satellite observations and to use a well defined protocol to make statistical analysis. This has led the participants of Japanese project "Frontier-NASDA" to re-analyse Intercosmos-19, Intercosmos-24 and Aureol-3 data (Afonin et al., 1999; Molchanov et al., 2002). This research was continued in a frame of Russian-Japanese ISTC project 1121 devoted to organization complex observation at Karimshino observatory (Molchanov et al., 2004a) and as a result of preparation to French satellite project DEMETER (Hobara et al., 2004).

In the paper by Molchanov et al. (2004a) based on plasma density data from the Cosmos-900 satellite the spatial distribution of the ionospheric turbulence in a form $k^{-b}$ have been analyzed, where $k$ is wave number and $b$ is the fractal index. In this case spatial scales $\left(l=k^{-1}\right)$ are ranging from 15 to $300 \mathrm{~km}$ at the satellite height $h=450-500 \mathrm{~km}$. Depending on season, local time and seismic activity, the index $b$ varies in the interval 1.3-1.9. Then the slope of the spatial distribution for electric field turbulence observed on board the Intercosmos-24 satellite $(h=500-700 \mathrm{~km}, l$ scales of several meters) has been considered. Supposing a simple connection between the power spectrum density of the plasma and the electric field it is found $b \sim 1.2-1.7$. They have found that intensification of the turbulence near the magnetic equator is definitely connected with the presence of the equatorial density anomaly (EA) but the existence of the regular moderate level aside of EA and at the mid-latitude ionosphere invokes a possibility of another energy source, probably atmospheric gravity waves. Hobara et al. (2004) using the power spectrum distribution (PSD) data on electron density and electric field variations observed on board of Aureol-3 satellite at middle ionosphere analyze a scale distribution of the ionospheric turbulence At first, the high-resolution data in the near-equator region for several orbits have been processed. In this case the frequency range is from $6 \mathrm{~Hz}$ to $300 \mathrm{~Hz}$ (corresponding spatial scales from $27 \mathrm{~m}$ to $1.3 \mathrm{~km}$ ), each power spectrum obey a single power low fairly well, and the mean spectral indices are rather stable with $b_{N}=2.2 \pm 0.3, b_{E}=1.8 \pm 0.2$ for the density and electric field, respectively. Then they produce a statistical study of electric field bursts in the frequency range $10-300 \mathrm{~Hz}$ from low-time resolution data (filter bank envelope). These bursts concentrate aside of Equatorial Anomaly depletion (geomagnetic latitude $30-40^{\circ}$ ) and their fractal indices vary in the interval $b_{E}=2.0-2.5$. We conclude that the ionospheric turbulence is a unique process in a large interval of scales from hundreds $\mathrm{km}$ to several meters and the bdependence is similar to the classic Kolmogorov's turbulence $b=5 / 3$.

As for relation to seismicity, Molchanov et al. (2004a) divide their data on seismic orbits ( \pm 7 days around date and $\pm 1500 \mathrm{~km}$ near epicenter of large earthquakes, $M \geq 6$ ) and

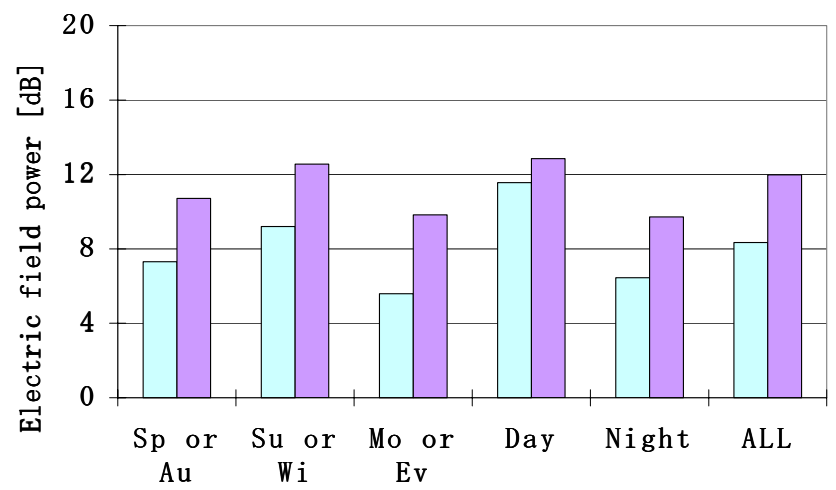

Fig. 5. Seasonal and local time dependence of the averaged electric field power of the burst events. Shadowed bins represent the bursts with major seismic activities and white bins are for the burst without seismic activity. It is data of Aureol-3 satellite at altitudes $500-700 \mathrm{~km}$ in the magnetic latitude interval $\pm 45^{\circ}$ (adopted from Hobara et al., 2004).

on nonseismic orbits and have discovered reliable depression of ionospheric turbulence in a range of scales $40-400 \mathrm{~km}$ in connection with seismic activity. With the same type of analysis Hobara et al. (2004) have revealed a clear tendency for increase of the turbulence average intensity for scales 27 $1300 \mathrm{~m}$ on about $3-4 \mathrm{~dB}$ during the periods of seismic activity. Their statistics is shown in Fig. 5. It means that there is an evident short-term modification of the ionospheric turbulence due to earthquake influence the ionosphere.

\subsection{Depression of ULF noise from the magnetosphere and ionosphere}

Molchanov et al. $(2003,2004 b)$ present the results of ULF magnetic field observation at Karimshino station (Kamchatka, Russia) during 13 months of regular observation. During this period about 20 rather intensive and nearby seismic shocks happened, and it was possible to produce both case study and statistics. The spectra of ULF intensity for each magnetic field component $(\mathrm{H}, \mathrm{D}, \mathrm{Z})$ in the 7 frequency bands: $\mathrm{F}=0.003-0.01 \mathrm{~Hz}$ (channel 1), $\mathrm{F}=0.01-0.03 \mathrm{~Hz}$ (channel2), $\mathrm{F}=0.03-0.1 \mathrm{~Hz}$ (channel 3), $\mathrm{F}=0.1-0.3 \mathrm{~Hz}$ (channel 4), $\mathrm{F}=0.3-1.0 \mathrm{~Hz}$ (channel 5), $\mathrm{F}=1.0-3.0 \mathrm{~Hz}$ (channel 6) and $\mathrm{F}=3.0-5.0 \mathrm{~Hz}$ (channel 7) was analyzed for the beginning and conventional correlation with $K p$ index of global magnetic activity and evident daily variation were found. But no clear signature of correlation with $K s$ (i.e. seismicity) has been discovered with such a type of analysis. Then they used the method of polarization ratio and some correlation with $K s$ became evident at least for the frequency channels 2 and 3. Demonstration of such a correlation for the strongest seismic events (in terms of $K s$ value) is shown in Fig. 6. Each case covers a time interval \pm 14 days around the EQ date and the presentation is centered to the corresponding date. For simplicity, only the channel $2(\mathrm{~F}=0.01-0.03 \mathrm{~Hz})$ is presented here. It is obvious that nighttime values of $Z / G$ show increase at about 2-7 days time period before EQ date. 

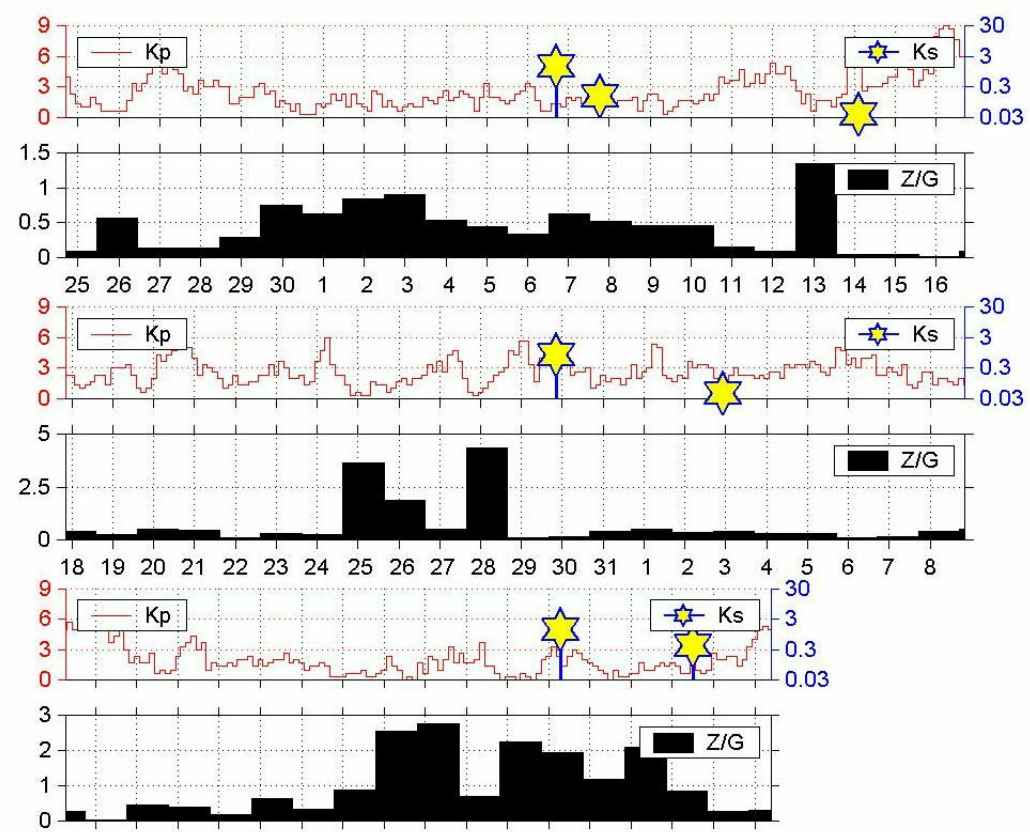

$\begin{array}{lllllllllllllllll}13 & 14 & 15 & 16 & 17 & 18 & 19 & 20 & 21 & 22 & 23 & 24 & 25 & 26 & 27 & 28 & 29\end{array}$
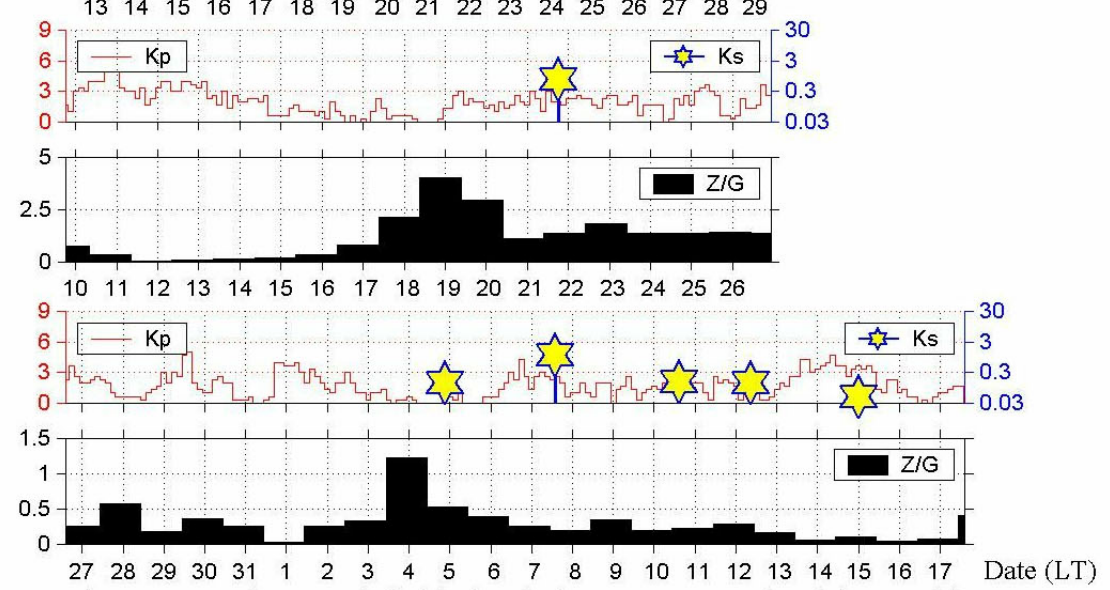

Fig. 6. Changes of ULF magnetic field impedance ratio $(Z / G)$ in the interval \pm 14 days around date of 5 strongest seismic shocks during period of observation at Karimshino station (see text, from Molchanov et al., 2003).

Molchanov et al. raise an important question, whether the effect is due to increase of $Z$ component, or it is due to decrease of $G$ component, or both? The behavior of $Z$ component is characterized by essential seasonal variation, sometimes it is exposed to small man-made perturbations, but it shows no correlation with seismicity. The comparison of the behavior of $Z / G$ and $1 / G$ has shown that the effect of suppression of ULF intensity about $2-6$ days before rather strong and isolated seismic shocks (magnitude $\mathrm{M}=4.6-6.6$ ) is observed indeed. It is revealed for nighttime and horizontal component of ULF field $(G)$ in the frequency range $0.01-0.1 \mathrm{~Hz}$.

They prove the reliability of the effect by computed correlation between $G$ (or $1 / G$ ) and seismic indexes $K s$ for the rather long period of observation from June 2000 to AprilMay 2002.

As for interpretation, two models were discussed and computed: the first is decrease of penetration coefficient of
Alfvén waves from magnetosphere due to turbulent increase of effective Pedersen conductivity in the ionosphere, and the second is a change of wave number $(k)$ distribution of source ionospheric turbulence. One of the mechanisms or both could be responsible for observed 2-3 times suppression of ULF magnetic field noise at the ground.

They conclude that assumption on modification of ionospheric turbulence is rather useful for explanation of these results of ULF observation on the ground.

\section{Mechanism of LAICS}

Several types of lithosphere processes can influence the ionosphere including the gas-water diffusion, the volcano eruptions and the seismicity. Here we will mainly discuss processes related to seismicity. It is the reason why we refer to 


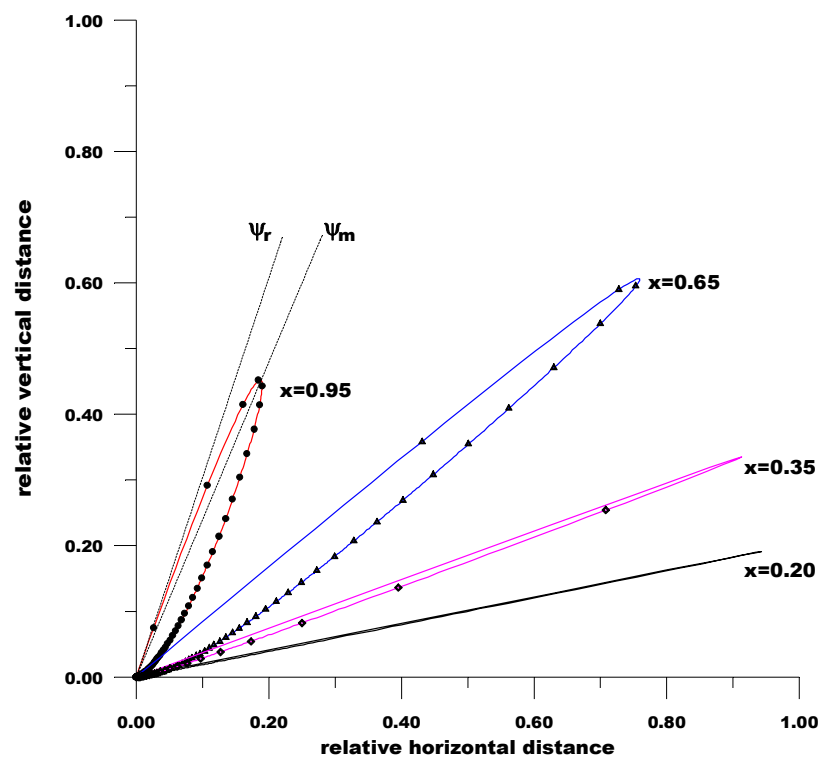

Fig. 7. Ray diagrams for different relative frequencies $x=\omega / \mathrm{N}$. Meaning of resonant ray angle $\psi r$ and maximum radiation angle $\psi m$ are explained by dashed lines. All the ray values $p(x, \psi)$ are multiplied $x^{3}=\cos ^{3} \psi r$ for convenience of presentation (from Mareev et al., 2002).

Lithosphere-Atmosphere-Ionosphere Coupling due to Seismicity (LAICS). Atmosphere is included in the coupling either as a passive or as an active intermediate element. It was recognized that the direct penetration from the ground of electromagnetic fields (Molchanov et al., 1995) and quasisteady electric fields (Pierce, 1976), which may be observed in seismically-active regions, could not be very effective. On the other hand, while penetrations of acoustic waves from seismic pulse have been registered (e.g. Blanc and Jacobson, 1989), their duration has been found to be too short for the excitation of the events observed. Indeed, if one wants to explain all the observations, it is probably more promising to look for indirect relationships linked to lithosphereionosphere coupling than to focus on electromagnetic or acoustic wave propagation. At present there is general consensus that only the Atmospheric Gravity Waves (AGW) can be responsible for the indirect coupling. This possibility was analyzed in many papers (Nekrasov et al., 1995; Gokhberg et al., 1995; Liperovsky et al., 2000). Important details of the process including transportation time of AGW energy, focusing and transformation to ionospheric plasma densityelectric field turbulence were discussed in the recent papers (Mareev et al., 2002; Molchanov, 2004). Shortly, the basics of the mechanism follows:

a) Sporadic water/gas eruptions during EQ preparation process produce near-surface temperature and density/velocity variations, which are the source of AGW energy flux into the atmosphere:

$P_{z}^{0}(\omega) \sim\left(\rho C s^{2} F(x) H_{z} / 2\right) \sum_{i=1}^{N_{s}} a_{L i}^{2}$,

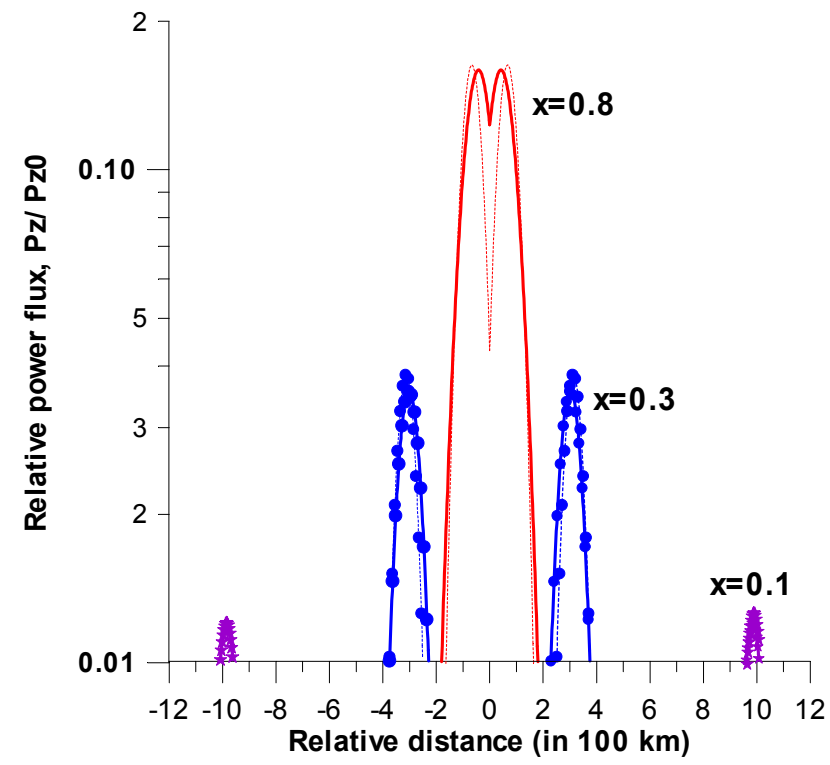

Fig. 8. AGW power flux $P_{z}(\omega)$ at height $h=100 \mathrm{~km}$ as ratio to power flux just above the source (height of the upper source boundary $H_{z}=100 \mathrm{~m}$ ) in dependence on horizontal distance from projection of the source center and for different relative frequencies $x=\omega / \omega_{g}$, where $\omega_{g}$ is Brant-Vaisala frequency. Dash line is for $k_{0} L=1(L \sim 12.5 \mathrm{~km})$ and solid line for $k_{0} L=2(L \sim 25 \mathrm{~km})$ (from Molchanov, 2004a).

where is vertical power flux just above the near-surface layer of the turbulent variations, $\rho$ is atmospheric density, $C s$ is sound velocity, $H_{z}$ is thickness of the layer and $a_{L i}^{2} \approx<\delta T^{2} / T^{2}+\delta \rho^{2} / \rho^{2}>$ is intensity of turbulent variation of temperature $(T)$ and density in each "spot" of the correlated variations, number of $N_{s}, F(x)$ is normalized frequency distribution, $x=\omega / \omega_{B}$ is normalized frequency and $\omega_{B}=2 \pi / \tau_{B}$ is characteristic Brant-Vaisala frequency ( $\tau_{B} \sim 6 \mathrm{~min}$ ). Referring to observational data Ns $\sim 2-5, \sim 1-$ $2^{\circ}$ (Tronin et al., 2004) and $a_{L i}^{2} \sim 10^{-5}$.

b) There is space-frequency discrimination of the AGW energy in the atmosphere because focusing depends on frequency as it is shown in Fig. 7. Main impact in the atmosphere-ionosphere boundary is expected for the frequency range $x=0.1-0.9$ (wave periods $\tau_{w} \sim 7-60 \mathrm{~min}$ ) and horizontal distances $\pm 100-1000 \mathrm{~km}$ above the source center as shown in Fig. 8.

c) Supposing neutral wind in the ionosphere with velocity $V_{n} \sim 100 \mathrm{~m} / \mathrm{s}$ the slow convective eigenmode oscillations of charged particle density $\mathrm{n}$ and electric field are possible $\left(\omega \approx k V_{d i}\right.$, where ion drift velocity $V_{d i} \leq V_{n}$ for altitudes range between 90 and $150 \mathrm{~km}$ ). Pumping of these oscillations by regular large-scale AGW turbulence (scales $l \sim 1000 \mathrm{~km}$ ) creates the ionospheric turbulence of the Kolmogorov's type. However, during seismic activity a modification of ionospheric turbulence is possible due to generation of related to seismicity AGW with horizontal scales $10-50 \mathrm{~km}$. The interaction of the AGW with the ionospheric turbulence is especially efficient if matching condition (equality of AGW 


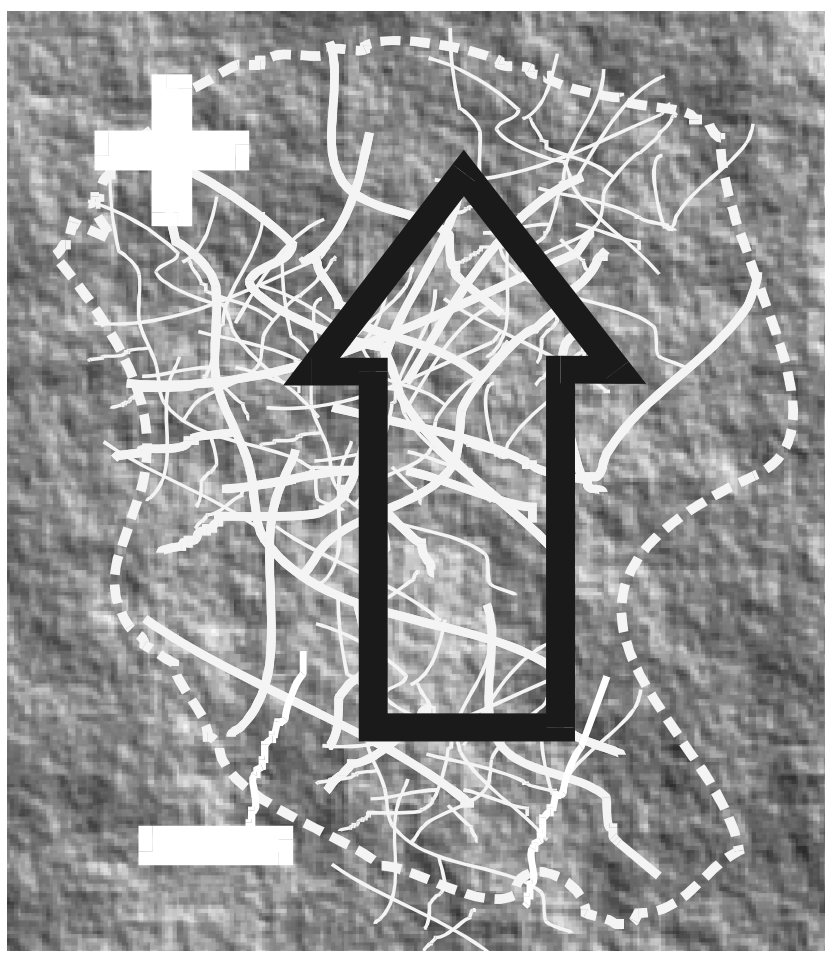

Fig. 9. Scheme of fluid saturated open pore network ("bubble"), which can move upward by Archimedean force with excess of stress $\Delta \sigma \approx \Delta \rho \phi g R$ in the upper part of the network and the same deficit of stress below. $\Delta \rho$ is difference in density of solid and fluid matter, $\phi$ is porosity, $g$ is gravity acceleration and $R$ is size of the network.

and convective mode group velocities) is fulfilled. Under this condition, the favorite frequency range $x \approx 0.2-0.4\left(\tau_{w} \approx 15-\right.$ $30 \mathrm{~min})$ is obtained. In this case, variation of wind velocity, which produces source currents in the lower ionosphere can reach values $\sim 3-5 \mathrm{~m} /(\mathrm{s} \sqrt{ } \mathrm{Hz})$ at the near-equatorial region (Molchanov, 2004).

d) The theoretical scheme presented here includes all the above-mentioned observational evidences, taking into account that scattering on AGW-induced atmosphereionosphere perturbations leads to depression of radio-signals and ULF magnetospheric emission on the ground.

\section{Discussion}

We tried to show that the assumption about fluid eruption at the ground surface is quite sufficient to explain the atmosphere-ionosphere perturbations during the preparation stage of an earthquake. A question arises immediately: what means earthquake preparation process in a large zone order of hundred kilometers as it is followed from abovementioned observational facts and from observation of nearseismic effects (e.g. Molchanov et al., 2004c)? It is evident that conventional seismology theories (nucleation, dilatancydiffusion, dilatancy instability, consolidation and so on) have failed to explain neither our results, nor seismic data itself (a)

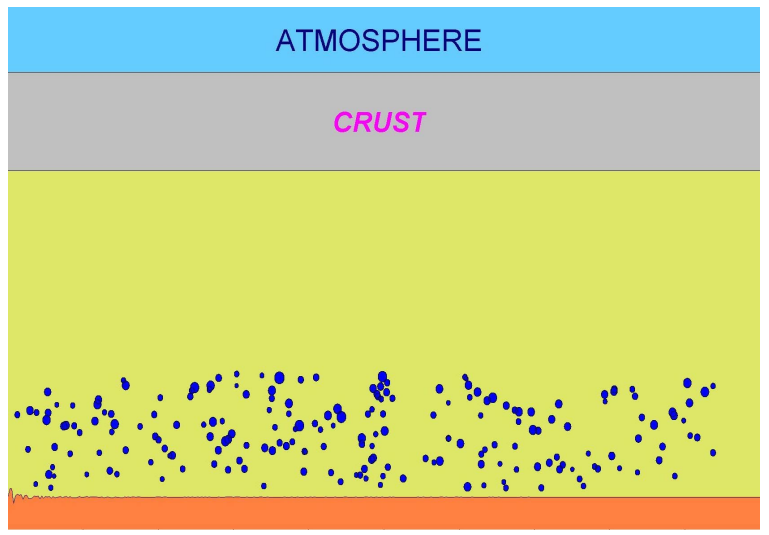

(b)

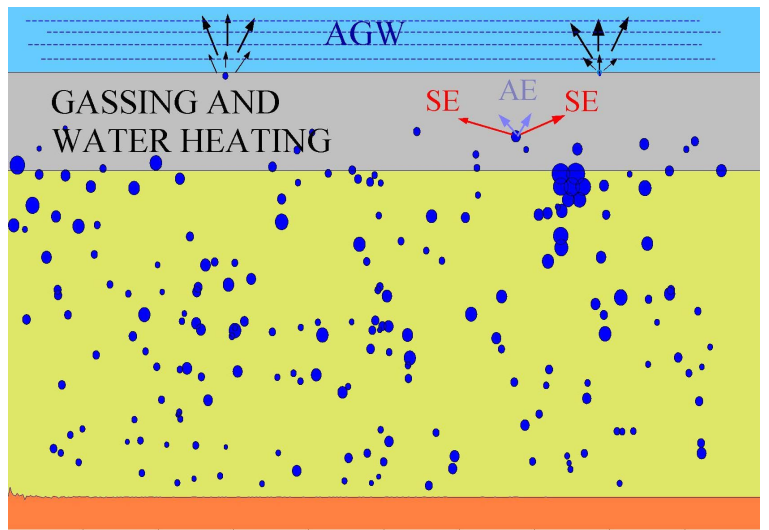

(c)

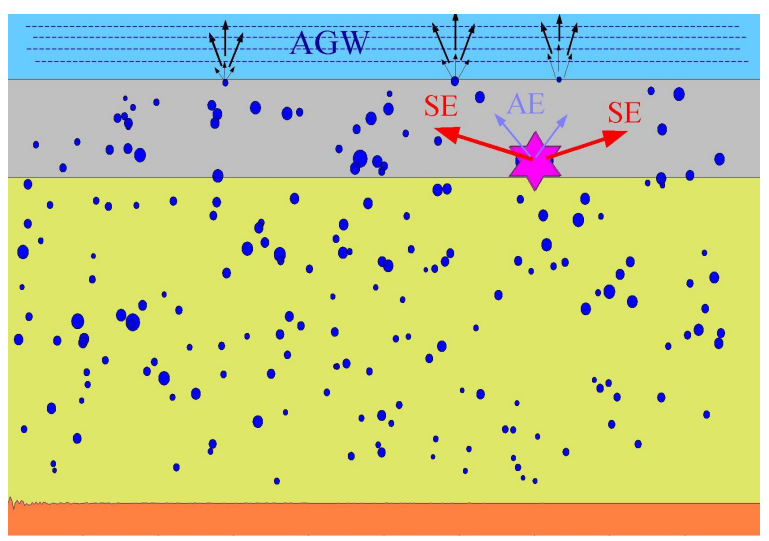

Fig. 10. Stages of earthquake preparation: (a) Appearance of small bubbles ensemble beneath lithosphere as perturbation of heat flow from the interior; (b) Preseismic stage: entrance of the bubbles into the crust, their merging, appearance of temperature and density perturbation near the ground surface and weak foreshock activity inside crust; (c) Near-seismic stage and main shock: further merging of the bubbles in the selected areas, intensification of SA and ULF magnetic field foreshocks, eruption of large bubbles after upward migration in the strength-weakened site with creation of the main shock.

(absence of large stress accumulation and dilatancy, existence of deep EQs etc.).

However, rather suitable ideas have already appeared. It was established that seismogenic faulting is commonly associated with zones of fluid overpressure (e.g. Sibson, 1990; 
Yamashita, 1997). Stein et al. (1992) provide a mechanism for stress changes focusing over distances of $100 \mathrm{~km}$, probably related to small fluid volumes. Byerlee (1993) proposes a rupture of discontinuous pockets of high pore pressure to produce episodic flow before EQs. Fenoglio et al. (1995), basing on Byerlee model, discussed rupturing of small, isolated fluid reservoirs in the fault zone leading to unsteady fluid flow and ULF magnetic field signals. It was recognised that gas can play a fundamental role in the earthquake preparation process (e.g. Gold and Vogel, 1992). At last Iudin et al. (2002) proposed a model of EQ triggering due to fluid saturated pore association ("bubble") upward migration; and Yunga et al. (2002) found fast upward migration of foreshocks position and slow upward migration of EQs hypocenters in Kamchatka seismic data, while Korovkin et al. (2002) produced the finite-automation modelling of the bubble merging in a course of the upward migration. Their mechanism of ascending migration of fluid saturated pore association with variable porosity due to percolation instability in gravitational field is illustrated in Fig. 9.

Supposed development of earthquake preparation process is shown in Fig. 10.

This theoretical model allows explaining the observational facts: large region of precursor distribution, both preseismic and near-seismic events, possibility of deep earthquake etc. Indeed it looks as not very speculative, taking into consideration that seismic energy released each year is about $1 \%$ of the yearly amount of heat energy reaching the Earth's surface from the interior (Ben-Menahem, 1995).

So our conclusions (general concept) are reduced to the following:

1. Upward migration of gas/liquid substrate matter (bubble) could lead to ousting of the water/gas near the ground surface and to origin of EQ itself in the strengthweakened area.

2. Time and place of the bubble appearance could be random values, but EQ, geochemistry anomaly and foreshocks (seismic, SA and ULF electromagnetic ones) are casually connected.

3. Atmospheric perturbation of temperature and density could follow preseismic water/gas release resulting to generation of internal gravity waves with periods 660 min.

4. Seismo-induced AGW could lead to modification of the ionospheric turbulence and to a change of over-horizon radio-wave propagation in the atmosphere, reflection of LF wave from the lower ionosphere and ULF emission depression at the ground.

Acknowledgements. Authors are thankful to S. Uyeda for helpful discussion of the results. This research have been performed under ISTC grant 1121.

Edited by: M. Contadakis

Reviewed by: M. Parrot and another referee

\section{References}

Afonin, V. V., Molchanov, O. A., Kodama, T., Hayakawa, M., and Akentieva, O. A.: Statistical study of ionospheric plasma response to seismic activity: search for reliable result from satellite observations, in Atmospheric and Ionospheric Electromagnetic Phenomena Associated with Earthquakes, edited by Hayakawa, M., Terra Sci. Publ. Comp., 597-618, 1999.

Ben-Menahem, A.: Review, A concise history of mainstream seismology: Origins, Legacy and Perspectives, BSSA, 85, 1202 1225, 1995.

Biagi, P. F., Ermini, A., Kingsley, S. P., Khatkevich, Y. M., and Gordeev, E. I.: Possible precursors in groundwater ions and gases in Kamchatka (Russia), Phys. Chem. Earth, 25, 295-305, 2000.

Biagi, P. F., Molchanov, O. A., Piccolo, R., Minafra, A., Ermini, A., Capozzi, V., Khatkevich, Y. M., and Gordeev, E. I.: Copostseismic hydrogeochemical anomalies in a volcanic Environment, Nat. Haz. Earth Sys. Sci., 3, 263-267, 2003,

SRef-ID: 1684-9981/nhess/2003-3-263

Biagi, P. F., Piccolo, R., Ermini, A., Martellucci, S., Bellecci, C., Hayakawa, M., Capozzi, V., and Kingsley, S. P.: Possible earthquake precursors revealed by LF radio signals, Nat. Haz. Earth Sys. Sci., 1, 99-104, 2001,

SRef-ID: 1684-9981/nhess/2001-1-99.

Biagi, P. F., Piccolo, R., Castellana, L., Ermini, A., Martellucci, S., Bellecci, C., Capozzi, V., Perna, G., Molchanov, O., and Hayakawa, M.: Variations in a LF radio signal on the occasion of the recent seismic and volcanic activity in Southern Italy, Phys. Chem. Earth, 29, 551-557, 2004.

Blanc, E. and Jacobson, A. R.: Observation of ionospheric disturbances following a 5-kt chemical explosion, 2. Prolonged anomalies and stratifications in the lower thermosphere after shock passage, Radio Sci., 24, 739-746, 1989.

Byerlee, J.: Model for episodic flow of high pressure water in fault zones before earthquakes, Geology, 21, 303-306, 1993.

Dey, S. and Singh, R. P.: Surface Latent Heat Flux as an Earthquake Precursor, Nat. Haz. Earth Sys. Sci., 3, 749-755, 2003,

SRef-ID: 1684-9981/nhess/2003-3-749.

Diakonov, B. P., Karryev, B. S., Khavroshkin, O. B., Nikolaev, A. V., Rykunov, L. N., Seroglazov, R. R., Trijanov, A. K., and Tsyplakov, V. V.: Manifestation of earth deformation process by high frequency seismic noise characteristics, Phys. Earth Planet. Inter., 63, 151-162, 1990.

Fenoglio, M. A., Johnston, M. J. S., and Byerlee, J. D.: Magnetic and electric fields associated with changes in high pore pressure in fault zone-application to the Loma Prieta ULF emissions, J. Geophys. Res., 100, 12 951-12 958, 1995.

Fraser-Smith, A. C., Bernardi, A., McGill, P. R., Ladd, M. E., Helliwell, R. A., and Villard, O. G.: Low-frequency magnetic field measurements near the epicenter of the Ms=7.1 Loma Prieta earthquake, Geophys. Res. Lett., 17, 1465-1468, 1990.

Fukumoto, Y., Hayakawa, M., and Yasuda, H.: Reception of overhorizon FM transmitter signals and their association with earthquakes, in Seismo-Electromagnetics (Lithosphere-AtmosphereIonosphere Coupling), edited by Hayakawa, M. and Molchanov, O., Terrapub, 452-458, 2002.

Ghose. D., Das, N. K., and Sinha, B.: Anomalous Helium Emission - Precursor to Earthquakes, Current Science, 71, 56-581, 1996.

Gokhberg, M. B., Morgounov, V. A., and Pokhotelov, O. A.: Earthquake prediction: Seismoelectromagnetic phenomena, ReadingPhiladelphia., Gordon and Breach Science Publishers, 287, 1995.

Gokhberg, M. B., Gufeld, I. L., Rozhnoi, A. A., Marenko, V. F., 
Yampolshy, V. S., and Ponomarev, E. A.: Study of seismic influence on the ionosphere by superlong wave probing of the Earth-ionosphere waveguide, Phys. Earth Planet. Inter., 57, 6467, 1989.

Gold, T. and Vogel, J. E.: Hydraulic-elastomeric mount displacement decoupler, The Journal of the Acoustical Society of America, 83, 844-851, 1992.

Gordeev, E. I., Droznin, D. V., Kasahara, M., Levina, V. I., Leonov, V. L., Miyamachi, H., Okayama, M., Saltykov, V. A., Sinitsyn, V. I., and Chebrov, V. N.: Seismic Events Associated with the 1996 Volcanic Eruptions in the Karymsky Volcanic Center, (English version), Volc. and Seismol., 19, 713-735, 1998.

Gorbatikov, A. V., Molchanov, O. A., Hayakawa, M., Uyeda, S., Hattori, K., Nagao, T., Nikolaev, A. V., and Maltsev, P.: Acoustic emission, microseismicity and ULF magnetic field perturbation related to seismic shocks at Matsushiro station, in Seismo-Electromagnetics (Lithosphere-Atmosphere-Ionosphere Coupling), edited by Hayakawa, M. and Molchanov, O., Terrapub, 1-10, 2002.

Gufeld, I. L., Rozhnoi, A. A., Tyumensev, S. N., Sherstuk, S. V., and Yampolsky, V. S.: Radiowave disturbances in period to Rudber and Rachinsk earthquakes, Phys. Solid Earth, 28, 267-270, 1992.

Hayakawa, M., Molchanov, O. A., Ondoh, T., and Kawai, E.: The precursory signature effect of the Kobe earthquake on subionospheric VLF signals, J. Comm. Res. Lab., 43, 169-180, 1996.

Hayakawa, M.: Electromagnetic Precursors of Earthquakes: Review of Recent Activities, Rev. Radio Sci., 1993-1995, Oxford Univ. Press, 807-818, 1997.

Hobara, Y., Lefeuvre, F., Parrot, M., and Molchanov, O. A.: Low latitude ionospheric turbulence and possible association with seismicity from satellite Aureol 3 data, Annales Geophys., in press, 2004.

Iudin, D. I., Korovkin, N. V., Molchanov, O. A., Surkov, V. V., and Hayakawa, M.: Model of earthquake triggering due to gas-fluid "bubble" upward migration, I. Physical Rationale, in Seismo-Electromagnetics (Lithosphere-Atmosphere-Ionosphere Coupling), edited by Hayakawa, M. and Molchanov, O., Terrapub, 177-185, 2002.

King, C. Y.: Gas Geochemistry Applied to Earthquake Prediction An Overview, J. Geophys. Res., 91, 2269-2281, 1986.

Kopytenko, Y. A., Matiashvili, T., Voronov, P. M., Kopytenko, E. A., and Molchanov, O. A.: Detection of ultralow-frequency emissions connected with the Spitak earthquake and its aftershock activity, based on geomagnetic pulsation data at Dusheti and Vardzia observatories, Phys. Earth Planet. Inter., 77, 88-95, 1993.

Korovkin, N. V., Iudin, D. I., Molchanov, O. A., Hayakawa, M., and Surkov, V. V.: Model of Earthquake Triggering due to Gas-Fluid "Bubble" Upward Migration. II. FINITEAUTOMATON MODEL, in Seismo-Electromagnetics (Lithosphere-Atmosphere-Ionosphere Coupling), edited by Hayakawa, M. and Molchanov, O., Terrapub, 186-194, 2002.

Kushida, Y. and Kushida, R.: On a Possibility of Earthquake Forecast by Radio Observation in the VHF Band, RIKEN Review, 19, 152-160, 1998.

Liperovsky, V. A., Pokhotelov, O. A., Liperovskaya, E. V., Parrot, M., Meister, C.-V., and Alimov, O. A.: Modification of sporadic E-layers caused by seismic activity, S. Geophys, 21, 449-486, 2000.

Mareev, E. A., Iudin, D. I., and Molchanov, O. A.: Mosaic source of internal gravity waves associated with seismic activity, in Seismo-Electromagnetics (Lithosphere-Atmosphere-Ionosphere
Coupling), edited by Hayakawa, M. and Molchanov, O., Terrapub, 335-342, 2002.

Miyaki, K., Hayakawa, M., and Molchanov, O. A.: The role of gravity waves in the lithosphere-ionosphere coupling, as revealed from the subionospheric LF propagation data, in Seismo-Electromagnetics: Lithosphere-Atmosphere-Ionosphere Coupling, edited by Hayakawa, M. and Molchanov, O., Terrapub, 229-232, 2002.

Molchanov, O. A.: On the origin of low- and middle-latitude ionospheric turbulence, Phys. Chem. Earth, 29, 559-567, 2004.

Molchanov, O. A., Kopytenko, Y. A., Kopytenko, E. A., Matiashvili, T., Fraser-Smith, A. C., and Bernardi, A.: Results of ULF magnetic field measurements near the epicenters of the Spitak $(\mathrm{Ms}=6.9)$ and Loma Prieta $(\mathrm{Ms}=7.1)$ earthquakes: Comparative analysis, Geophys. Res. Lett., 19, 1495-1498, 1992.

Molchanov, O. A., Hayakawa, M., and Rafalsky, V. A.: Penetration characteristics of electromagnetic emissions from underground seismic source into the atmosphere, ionosphere and magnetosphere, J. Geophys. Res., 100, 1691-1712, 1995.

Molchanov, O. A. and Hayakawa, M.: Subionospheric VLF signal perturbations possibly related to earthquakes, J. Geophys. Res., 103, 17 489-17 504, 1998.

Molchanov, O. A, Hayakawa, M., Afonin, V. V., Akentieva, O. A., and Mareev, E. A.: Possible influence of seismicity by gravity waves on ionospheric equatorial anomaly from data of IK-24 satellite 1. Search for idea of seismo-ionosphere coupling, in Seismo-Electromagnetics (Lithosphere-Atmosphere-Ionosphere Coupling), edited by Hayakawa, M. and Molchanov, O., Terrapub, 275-285, 2002.

Molchanov, O. A., Schekotov, A. Y., Fedorov, E. N., Belyev, G. G., and E. E.: Gordeev, Preseismic ULF electromagnetic effect from observation at Kamchatka, Nat. Haz. Earth Sys. Sci., 3, 17, 2003.

Molchanov, O. A., Akentieva, O. S., Afonin, V. V., Mareev, E. A., and Fedorov, E. N.: Plasma density-electric field turbulence in the low-latitude ionosphere from the observation on satellites; possible connection with seismicity, Phys. Chem. Earth, 29, 569577, 2004a.

Molchanov, O. A., Schekotov, A. Y., Fedorov, E., Belyaev, G. G., Solovieva, M. S., and Hayakawa, M.: Preseismic ULF effect and possible interpretation, Ann. Geophysicae, 47, 121-133, $2004 \mathrm{~b}$.

Molchanov, O., Schekotov, A., Solovieva, M., Fedorov, E., Gladyshev, V., Gordeev, E., Chebrov, V., Saltykov, V., Sinitsin, V., Hattori, K., and Hayakawa, M.: Near-seismic effects in ULF fields and seismo-acoustic emission: statistics and explanation, Nat. Haz. Earth Sys. Sci., this issue, 2004c.

Morozova, L. I.: Features of atmo-lithmospheric relationships during periods of strong Asian earthquakes, Fizika Zemli, N5, 6368, 1996.

Nekrasov, A. K., Shalimov, S. L., Shukla, P. K., and Stenflo, L.: Nonlinear disturbances in the ionosphere due to acoustic gravity waves, J. Atmos. Terr. Phys., 57, 737-741, 1995.

Park, S. K.: Precursors to earthquakes: seismoelectromagnetic signals, Serv. Geophys., 17, 493-516, 1996.

Parrot, M., Achache, J., Berthelier, J. J., Blanc, E., Deschamps, A., Lefeuvre, F., Menvielle, M., Planet, J. L., Tarits, P., and Villain, J. P.: High-frequency seismo-electromagnetic effects, Phys. Earth Planet. Inter., 77, 65-83, 1993.

Pierce, E. T.: Atmospheric electricity and earthquake prediction, Geophys. Res. Lett., 3, 185-188, 1976.

Pinty, B., Gobron, N., Verstraete, M. M., Mélin, F., Widlowski, J.-L., Govaerts, Y., Diner, D. J., Fielding, E., Nelson, D. L., 
Madariaga, R., and Tuttle, M. P.: Observing Earthquake-Related Dewatering Using MISR/Terra Satellite Data, EOS, 84, 37-48, 2003.

Rikitake, T.: Earthquake prediction, Elsevier Scientific Publishing Company, Amsterdam-Oxford-New York, 357, 1976.

Rodger, C. J. and Clilverd, M. A.: Modeling of subionospheric VLF signal perturbations associated with earthquakes, Radio Sci., 34, 1177-1185, 1999.

Roeloffs, E. A.: Hydrologic precursors to earthquakes: a review, Pure Appl. Geophys., 126, 177-209, 1988.

Rozhnoi, A., Solovieva, M. S., Molchanov, O. A., and Hayakawa, M.: Middle latitude LF $(40 \mathrm{kHz})$ phase variations associated with earthquakes for quiet and disturbed geomagnetic conditions, Phys. Chem. Earth, 29, 589-598, 2004.

Scholz, C. H.: The Mechanics of Earthquakes and Faulting, Cambridge University Press, 439, 1990.

Shvets, A. V., Hayakawa, M., and Molchanov, O. A.: Subionospheric VLF monitoring for earthquake-related ionospheric perturbations., J. Atmos. Electr., 22, 87-99, 2002.

Sibson, R. H.: Rupture nucleation on unfavorably oriented faults, Bull. Seismol. Soc. Am., 80, 1580-1604, 1990.

Soloviev, O. V., Hayakawa, M., Ivanov, V. I., and Molchanov, O. A.: Seismo-electromagnetic phenomenon in the atmosphere in terms of 3D subionospheric radio wave propagation problem, Phys. Chem. Earth, 29, 639-647, 2004.

Stein, R. S., King, G. C. P., and Lin, J.: Changes in failure stress on the Southern San Andreas fault system caused by 1992 M=7.4 Landers earthquake, Science, 258, 1328-1332, 1992.
Tramutoli, V., Di Bello,G., Pergola, N., and Piscitelli, S.: Robust Satellite Techniques for Remote Sensing of Seismically Active Areas, Ann. Geophysicae, 44, 295-312, 2001.

Tronin, A. A.: Satellite thermal survey application for earthquake prediction, in: Atmospheric and ionospheric electromagnetic phenomena associated with earthquakes, edited by Hayakawa, M., Terrapub, 717-746, 1999.

Tronin, A. A., Biagi, P. F., Molchanov, O. A., Khatkevich, Y. M., and Gordeev, E. I.: Temperature variations related to earthquakes from simultaneous observation at the ground stations and by satellites, Phys. Chem. Earth, 29, 501-506, 2004.

Voitov, G. I. and Yunusov, S. S.: Isotope-Carbon Precursor of Strong Tectonic Earthquakes, Doklady Akademii Nauk, 346, 392-395, 1996.

Wakita, H.: Geochemical Challenge to Earthquake Prediction, PNAS, 93, 3781-3786, 1996.

Uyeda, S., Hayakawa, M., Nagao, T., Molchanov, O., Hattori, K., Orihara, Y., Gotoh, K., Akinaga, Y., and Tanaka, H.: Electric and magnetic phenomena observed before the volcano-seismic activity in 2000 in the Izu Island Region, Japan, PNAS, 99, 73527355, 2002.

Yamashita, T.: Mechanical effect of fluid migration on the complexity of seismicity, J. Geophys. Res., 102, 17, 797-817, 1997.

Yunga, S., Lutikov, A., Molchanov, O., and Hayakawa, M.: Upward migration of earthquakes as a hint on origin of foreshock activity and other related phenomena, in Seismo-Electromagnetics (Lithosphere-Atmosphere-Ionosphere Coupling), edited by Hayakawa, M. and Molchanov, O., Terrapub, 167-172, 2002. 